\title{
NEOPHLEPSIUS LINNAVUORI (HOMOPTERA, CICADELLIDAE, DELTOCEPHALINAE): DESCRIÇÃO DE CINCO ESPÉCIES NOVAS ${ }^{1}$
}

\author{
Keti Maria Rocha Zanol ${ }^{2}$
}

\begin{abstract}
Neophlepsius Linnavuori (Homoptera, Cicadellidae, DeltocephaLINAE): DESCRIPTION OF FIVE NEW SPECIES. Five new species of Neophlepsius Linnavuori, 1955 are described: $N$. peruvianus sp.n., $N$. abruptus sp.n., $N$. denticulatus sp.n., $N$. bifidus sp.n. and $N$. malkowskiae sp.n. (the first one from Peru and the remainder from Brazil). N. phorus Cheng, 1980 is a new synonym of $N$. gracilis (Osborn, 1923). KEY WORDS. Cicadellidae, Deltocephalinae, Homoptera, Neophlepsius
\end{abstract}

O material utilizado pertence as seguintes Instituições: Coleção de Entomologia Pe J.S. Moure, Curitiba, Paraná (DZUP); Coleção Entomológica Capão da Imbuia, Curitiba, Paraná (CECI); Museu de Zoologia, Universidade de São Paulo, São Paulo (MZSP); The Natural History Museum, Londres (BMNH).

As Instituições depositárias dos tipos são as seguintes: Carnegie Museum, USA (CMNH); Kansas State University, USA (KSU); United State National Museum, USA (USNM); National Museum of Viena, Austria (NMV); Hungarian National Museum, Hungria (HNM); Coleção Rauno Linnavuori depositada no U.S. National Museum (RL); Museu de La Plata, Argentina (MLP).

As localidades que se acham assinaladas com asterísco $\left(^{*}\right)$ representam um novo registro da espécie.

\section{Neophlepsius Linnavuori}

Neophlepsius Linnavuori, 1955: 118. Espécie-tipo: Phlepsius gracilis Osborn, 1923 (designação original).

Cabeça em vista dorsal, com margem anterior arredondada, de comprimento uniforme. Coloração geral amarela com manchas marrons. Região frontal microesculturada; região discal lisa. Ocelos, na margem anterior, visíveis de cima. Área ocelo-ocular menor que o diâmetro dos ocelos. Sutura coronal atingindo a metade da coroa. Olhos, em vista ventral, com emarginação omatidial. Face achatada, mais ou menos ampla, amarela ornada de marrom. Frontoclípeo levemente túmido. Sutura transclipeal reta. Anteclípeo tão longo quanto as genas; levemente mais largo no ápice; plano. Genas com bordos sinuosos formando uma reentrância abaixo dos olhos.

1) Contribuição número 997 do Departamento de Zoologia, Universidade Federal do Paraná.

2) Departamento de Zoologia, Universidade Federal do Paraná. Caixa Postal 19020, 81531-990 Curitiba, Paraná, Brasil. Bolsista do CNPq. 

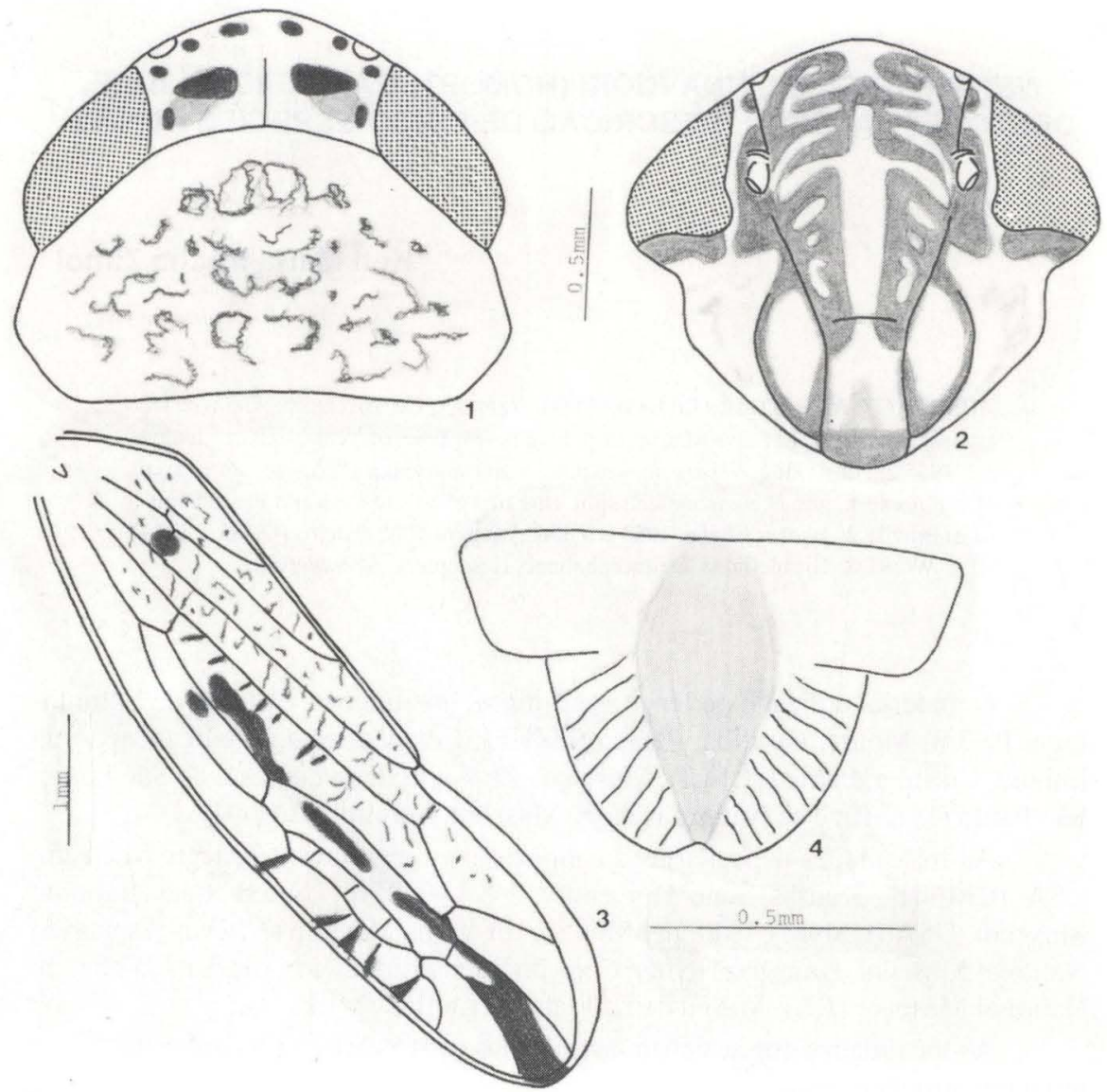

Figs 1-4. Neophlepsius gracilis (Osborn), fêmea. (1) Cabeça e pronoto, dorsal; (2) face; (3) tégmina; (4) sétimo esternito.

Pronoto tão largo ou mais largo que a cabeça; superfície lisa; amarela com manchas irregulares marrons; margens laterais carenadas. Tégminas com falsas veias, semitransparentes, com manchas marrons irregulares e dispersas; com duas células anteapicais fechadas e veias extranumerárias na primeira célula apical, anteapical externa, primeira célula discal e no clavo. Clavo e célula braquial com pontos esparsos marrons. Apêndice longo, alcançando a veia M3+4. Espinulação das tíbias anteriores $1+4$ e dos fêmures posteriores $2+2+1$.

Fêmea. Sétimo esternito com fenda mediana.

Macho. Pigóforo com macrocerdas; geralmente com apêndices, na margem ventral. Valva genital mais ou menos triangular. Placa subgenital mais ou menos triangular prolongada distalmente em um processo digitiforme, pouco esclerotinizado, mais ou menos rugoso com delicados pêlos; pouco antes deste processo, na superfície dorsal da placa, geralmente, com um dente esclerotinizado; macrocerdas unisseriadas. Apófise dos estilos de textura rugosa. Edeago simétrico, cilindrico e com apêndices. 
O gênero está constituído pelas seguntes espécies:

Neophlepsius multifarius (Berg, 1884)

Phlepsius multifarius Berg, 1884: 117-118 (Holótipo: MLP; Parátipo: DZUP).

Neophlepsius multifarius; Linnavuori, 1959: 192.

Neophlepsius macilentus Linnavuori, 1955: 119 (Holótipo NMV; Parátipo: RL).

Distribuição. Paraguai, Argentina, Uruguai, * Brasil (Mato Grosso).

Neophlepsius corpulentus Linnavuori, 1959

Neophlepsius corpulentus Linnavuori, 1959: 193-194 (Holótipo:NMV; Parátipos: HNM,RL).

Neophlepsius gracilis; Linnavuori, 1955: 118-119, non Osborn, 1923.

Distribuição. Brasil (Paraná, Santa Catarina, Rio Grande do Sul).

Neophlepsius disonymos Linnavuori, 1959

Neophlepsius disonymos Linnavuori, 1959: 194-195 (Holótipo: RL ?).

Distribuição. Brasil (* Paraná, Santa Catarina).

Neophlepsius bicuspidus Linnavuroi \& DeLong, 1979

Neophlepsius bicuspidus Linnavuori \& DeLong, 1979: 128 (Holótipo: sem indicação).

Distribuição. Brasil (São Paulo).

Neophlepsius rafaeli Zanol, 1988

Neophlepsius rafaeli Zanol, 1988: 52-53 (Holótipo e Parátipos: DZUP).

Distribuição. Brasil (Paraná, * Goiás), * Paraguai.

\section{Neophlepsius gracilis (Osborn, 1923)}

Figs $1-10$

Phlepsius gracilis Osborn, 1923: 57-58 (Holótipo: CMNH).

Neophlepsius gracilis; Linnavuori, 1955: 118.

Neophlepsius retrorsus Menzes, 1973: 131-132 (Holótipo: MZSP; Parátipos: MZSP, USNM).

Neophlepsius phorus Cheng, 1980: 103,105 syn.n. (Holótipo: KSU; Parátipos: KSU, USMN).

Região frontal da cabeça com quatro manchas arredondadas na margem anterior e uma atrás de cada ocelo, marrom-escuras. A região discal da coroa com duas manchas tranversas, ovaladas e duas longitudinais, logo atrás, próximas aos olhos, marrom-escuras. Sutura coronal marrom. Frontoclípeo com faixas oblíquas saindo junto à sutura frontoclipeal marrons. Anteclípeo com uma faixa transversa apical, marrom. Genas com uma faixa ao longo da sutura frontoclipeal, expandida lateralmente próximo à base das antenas, contornando externamente os alvéolos antenais e uma faixa transversa, abaixo dos olhos, marrom-escuras. Lora margeada de marrom. Margem costal, das tégminas, com manchas irregulares, marrom-escuras, junto à conexão das vênulas; manchas longitudinais na terceira célula apical, anteapical externa e na segunda discal e, uma arredondada sobre a veia extranumerária existente entre $1 \mathrm{~A}$ e a sutura claval, marrom-escuras. Primeira célula discal curta, não alcançando a célula anteapical externa. Veia transversa s-m na bifurcação da S ou antes. Veia transversa s ausente. 
Fêmea. Sétimo esternito com uma constricção lateral, no terço basal, formando um lobo com a margem posterior arredondada e uma reentrância no meio; rugosidades oblíquas, nos lados; uma mancha longitudinal, mediana, marrom-escura.

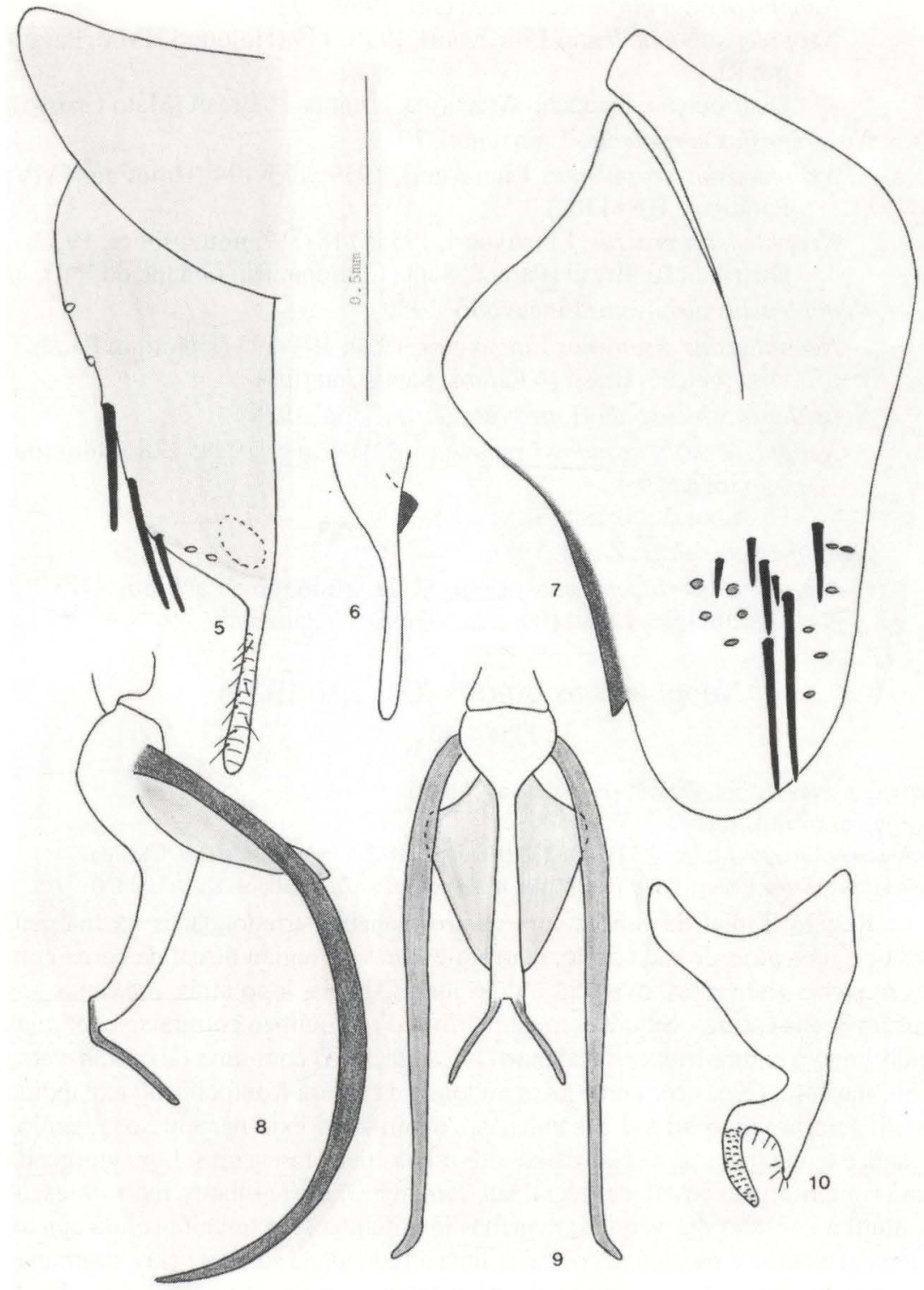

Figs 5-10. Neophlepsius gracilis (Osborn), macho. (5) Valva e placa subgenital; (6) dente da placa subgenital, lateral; (7) pigóforo, lateral; (8) edeago, lateral; (9) edeago, ventral; (10) estilo. 
Macho. Pigóforo com as margens ventrais esclerotinizadas e projetadas num pequeno apêndice pontiagudo. Placa subgenital com dente esclerotinizado, na superfície dorsal. Estilos falciformes. Edeago curvo para trás e para baixo, com um par de pequenos dentes na parte ventral, junto ao gonóporo; um par de apêndices basais, saindo lateralmente da base, curvos, paralelos entre si, voltados para trás e para baixo, mais longos que o edeago; um par de apêndices apicais, curtos, divergentes, voltados para para cima e para trás.

Comprimento (mm). Macho:6,76. Fêmea: 6,80.

Material examinado: Brasil (* Mato Grosso, Goiás, Rio de Janeiro, São Paulo, Paraná, Santa Catarina, Rio Grande do Sul). Bolívia (Província del Sara), *Paraguai.

Variações intraespecíficas. As faixas do frontoclípeo podem unir-se umas às outras deixando, entre si, áreas amarelas. A faixa transversa do anteclípeo evanescente para o meio e, ao mesmo tempo, expandindo-se medianamente em forma mais ou menos triangular. As manchas das genas, ao longo da sutura e abaixo dos olhos, podem fundir-se formando uma única mancha. As veias extranumerárias da primeira célula apical variam de 3 a 5 e as da célula anteapical externa variam de 1 a 5 . O número de veias extranumerárias pode variar nas tégminas direita e esquerda.

Discussão. Osborn (1923) caracterizou-a pelas manchas da cabeça, da face e das tégminas e pelo formato do sétimo esternito da fêmea. Linnavuori (1955) transferiu-a para Neophlepsius e, em 1959, colocou-a em sinonímia de $N$. multifarius (Berg) juntamente com N. macilentus Linnavuori (1955). Zanol (1988) após examinar os tipos de $P$. gracilis Osborn e P. multifarius Berg revalidou a espécie e colocou $N$. retrorsus Menezes em sinonímia.

Neste trabalho, apesar de não termos examinado $N$. phorus Cheng, colocâmo-la em sinonímia de $N$. gracilis após a análise dos desenhos e da sua descrição.

\section{Neophlepsius peruvianus sp.n.}

Figs 11-17

Holótipo macho. Padrão de coloração como em N. gracilis porém com manchas marom-claras. Primeira célula apical com duas veias extranumerárias. Célula anteapical externa sem veia extranumerária; uma mancha arredondada junto a veia extrenumerária entre $1 \mathrm{~A}$ e a sutura claval. Pigóforo com apêndices sinuosos e curvos, para frente e para os lados. Placa subgenital com dente esclerotinizado, na superfície dorsal. Estilos digitiformes, sem ângulo pré-apical distinto, ultrapassando a metade do comprimento da placa; apófise digitiforme; ápice, em vista lateral, obliquamente truncado. Edeago com um par de apêndices apicais, laterais e bífidos; os ramos menores voltados para frente; em vista lateral com uma das bordas serreadas e os ramos maiores direcionados para trás com as bordas lisas.

Fêmea. Desconhecida.

Comprimento (mm). Macho: 6,00.

Material. Holótipo macho. PERU. Huánuco, Tingo Maria; $1 \mathrm{~km}$ E. of town at edge of woodland 5.VIII.1971/ P.S. e H.L. Broomfield; BM 1971-486 (BMNH) 
Comentário. Esta espécie é aparentemente próxima a N. corpulentus diferindo pela coloração mais clara, pelo formato dos estilos e apêndices do edeago.

O nome da espécie é alusivo ao País onde o material-tipo foi coletado.

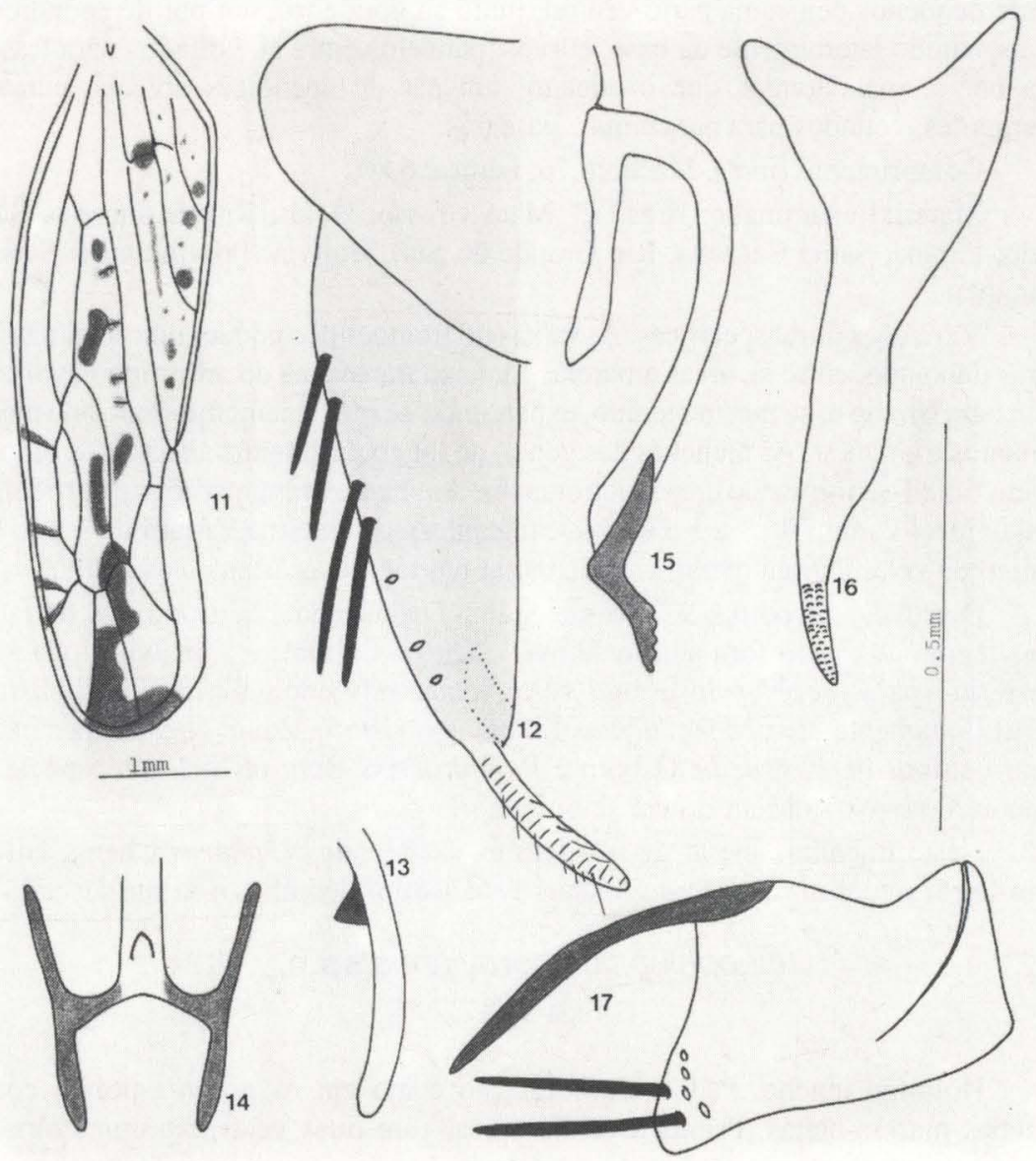

Figs 11-17. Neophlepsius peruvianus sp.n.. (11) Tégmina; (12) valva e placa subgenital; (13) dente da placa subgenital, lateral; (14) ápice do edeago, dorsal; (15) edeago, lateral; (16) estilo; (17) pigóforo, lateral.

\section{Neophlepsius abruptus sp.n.}

Figs 18-25

Holótipo fêmea. Padrão de coloração como em N. peruvianus sp.n. Tégmina esquerda com duas veias extranumerárias na célula anteapical externa e na primeira célula apical. Veia transversa s presente. Sétimo esternito com uma constricção lateral, no terço basal formando um lobo amplamente excavado no meio; uma mancha marrom-escura, contornando a fenda. 

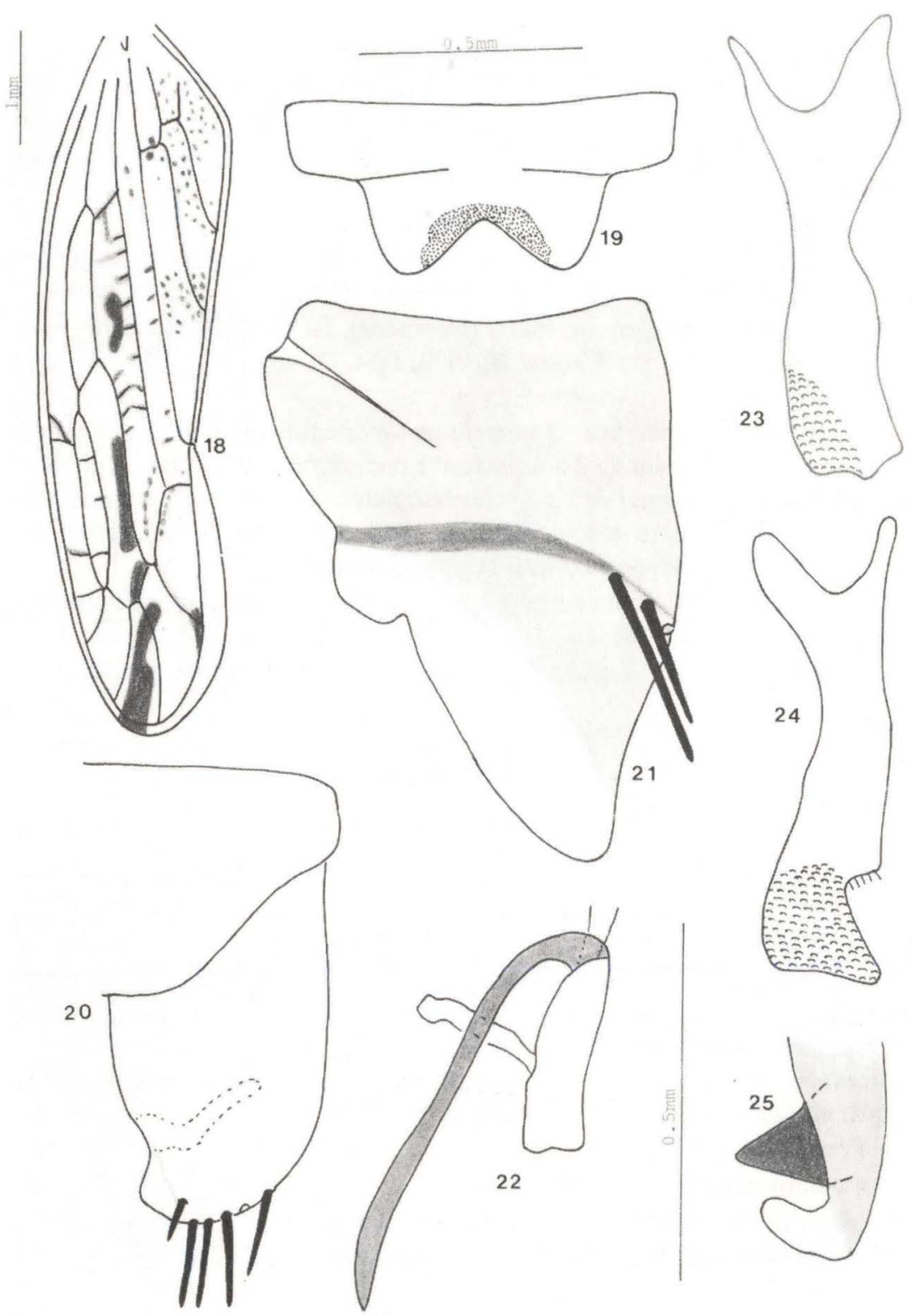

Figs 18- 25. Neophlepsius abruptus sp.n.. (18) Tégmina; (19) sétimo esternito da fêmea; (20) valva e placa subgenital; (21) pigóforo, lateral; (22) edeago, lateral; (23) estilo; (24) estilo, lateral; (25) dente da placa subgenital, lateral.

Macho. Clavo com uma mancha arredondada marrom-escura, junto à veia extranumerária entre 1A e a sutura claval. Pigóforo sem apêndices. Placa subgenital com o processo apical mais ou menos triangular, curto, tão longo quanto a sua 
largura basal, curvo para dentro. Estilos robustos, ultrapassando o dente interno da placa; em vista ventral, ápice truncado e sem ângulo pré-apical distinto; em vista lateral, apófise com ápice truncado e curvo para fora. Edeago com um par de apêndices basais, saindo lateralmente da base, sinuosos, aproximadamente o dobro do tamanho do edeago.

Comprimento (mm). Macho: 5,90. Fêmea: 6,70.

Material. Holótipo fêmea. BRASIL, Mato Grosso do Sul: Três Lagoas (Ilha Comprida), 8-11.XII.1972, R.F. Amaral Filho leg. (DZUP). Parátipos. Ibidem, 1 fềmea, 2 machos; Mato Grosso: Itaum (Dourados), III.1974, M. Alvarenga leg. (DZUP); Minas Gerais, Sta Vitoria/ III.1970, F.M. Oliveira leg., BM 1971-165 (BMNH).

Variação intraespecífica. O número de veias extranumerárias, das células anteapicais externa, variam de 2 a 4 , inclusive num mesmo indivíduo. A primeira célula apical pode apresentar de 1 a 3 veias extranumerárias; estas podem variar em um mesmo indivíduo. As macrocerdas da placa subgenital podem variar, em número, quando comparamos a esquerda com a direita.

Comentário. Esta espécie é próxima a $N$. rafaeli pela ausência de apêndices no pigóforo e formato do edeago.

O nome da espécie é alusivo a forma da placa subgenital e dos estilos do macho.

\section{Neophlepsius denticulatus sp.n.}

\section{Figs 26-31}

Holótipo macho. Padrão de coloração como em $N$. peruvianus sp.n.. Primeira célula apical com quatro veias extranumerárias na tégmina esquerda e três na direita. Célula anteapical externa com duas veias extranumerárias na tégmina esquerda e nenhuma na direita. Veia transversa s presente. Pigóforo com um par de apêndices convergentes, voltados para frente e para baixo. Superfície dorsal da placa subgenital sem dente esclerotinizado. Estilos digitiformes. Edeago com um par de apêndices apicais, convergentes e com inúmeros dentículos na borda externa, curvos para trás, ultrapassando a metade do edeago.

Fêmea. Desconhecida

Comprimento (mm). Macho: 4.70.

Material. Holótipo macho. BRAsIL, Paraná: Curitiba (Br 277-km8), II.1979, A.F. Yamamoto leg. (DZUP). Parátipo. 1 macho, com os seguintes dados MZUSP nr 20805 (MZSP).

Variação intraespecífica. A veia transversa s-m pode estar após a bifurcação da $\mathrm{S}$ em uma das tégminas.

Comentário. Aparentemente próxima a N. bifidus sp.n. por compartilharem da ausência do dente esclerotinizado da placa subgenital e por apresentar apêndices apicais no edeago.

O nome desta espécie é alusivo aos dentículos presentes nos apêndices do edeago. 


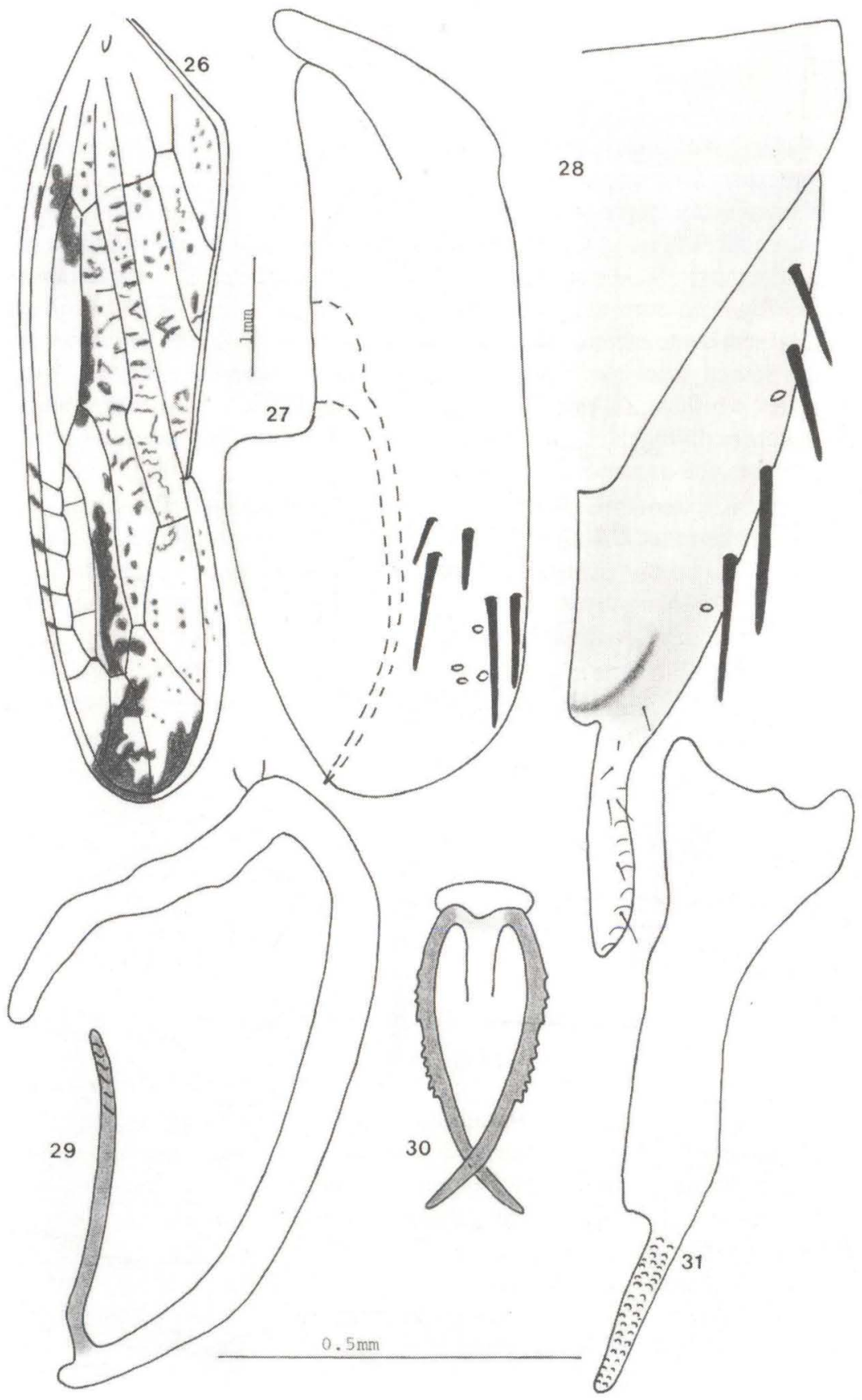

Figs 26-31. Neophlepsius denticulatus sp.n.. (26) Tégmina; (27) pigóforo, lateral; (28) valva e placa subgenital; (29) edeago, lateral; (30) apêndices do edeago, dorsal; (31) estilo. 


\section{Neophlepsius bifidus sp.n.}

Figs $32-38$

Holótipo macho. Padrão de coloração com em N. peruvianus sp.n.. Primeira célula apical com duas veias extranumerária na tégmina direita e quatro na esquerda. Célula anteapical externa sem veia extranumerária na tégmina direita e com uma veia extramunerária na esquerda. Primeira célula discal longa, alcançando a célula anteapical externa. Veia transversa s-m após a bifurcação da S. Veia transversa s presente. Pigóforo com um par de apêndices sinuosos, curvos para baixo. Placa subgenital sem dente esclerotinizado, na superfície dorsal. Estilos falciformes; ápice em vista lateral truncado. Edeago com um par de apêndices apicais, laterais, divergentes e bifídos; os ramos internos, paralelos, direcionados para frente e os ramos externos divergentes, curvos para os lados e para trás, aproximadamente duas vezes maiores que os ramos internos.

Fêmea. Externamente como o macho. Primeira célula apical com quatro veias extranumerárias. Célula anteapical externa sem veia extranumerária. Primeira célula discal curta, não alcançando a anteapical externa. Sétimo esternito mais ou menos retangular; margem posterior sinuosa com uma pequena reentrância no meio e dois pequenos lobos junto a reentrância.

Comprimento (mm). Macho: 6,00. Fêmea: 6,20.

Material. Holótipo macho. BRAsIL, Paraná: Castro, 19.VI.1984, A. Lara leg. (DZUP). Parátipos. Ibidem, 23.XII.1965, Marinoni \& Laroca leg., 1 macho; Ibidem, 19.IV.1984, A. Lara leg., 1 fêmea (DZUP); Palmeira, 13.II. 1984, T. Motta leg., 1 macho (CECI).

Comentário. Esta espécie aparentemente próxima a N. malkowskiae sp.n. por apresentarem os apêndices do edeago bifídos, ausência de dente na placa subgenital e formato do sétimo esternito da fêmea.

O nome da espécie é alusivo aos apêndices bifídos do edeago.

\section{Neophlepsius malkowskiae sp.n.}

\section{Figs $39-45$}

Holótipo macho. Padrão de coloração como em N. peruvianus sp.n.. Primeira célula apical com três veias extranumerárias na tégmina esquerda e duas na direita. Célula anteapical externa sem veia extranumerária na tégmina esquerda e uma na direita. Primeira célula discal longa, alcançando a anteapical externa, na tégmina direita e, curta, não alcançando a anteapical externa com uma veia extranumerária, na tégmina esquerda. Veia transversa $s-m$ na bifurcação da $S$ ou antes. Veia transversa s presente. Pigóforo com um par de apêndices ventrais, sinuosos, voltados para frente. Placa subgenital sem dente esclerotinizado na superfície dorsal. Estilos falciformes; em vista lateral com ápice truncado. Edeago curvo para cima, com um par de apêndices apicais bífidos; os ramos internos curvos para os lados e para cima e os ramos externos, aproximadamente três vezes maiores que os internos, curvos para trás e para baixo. 


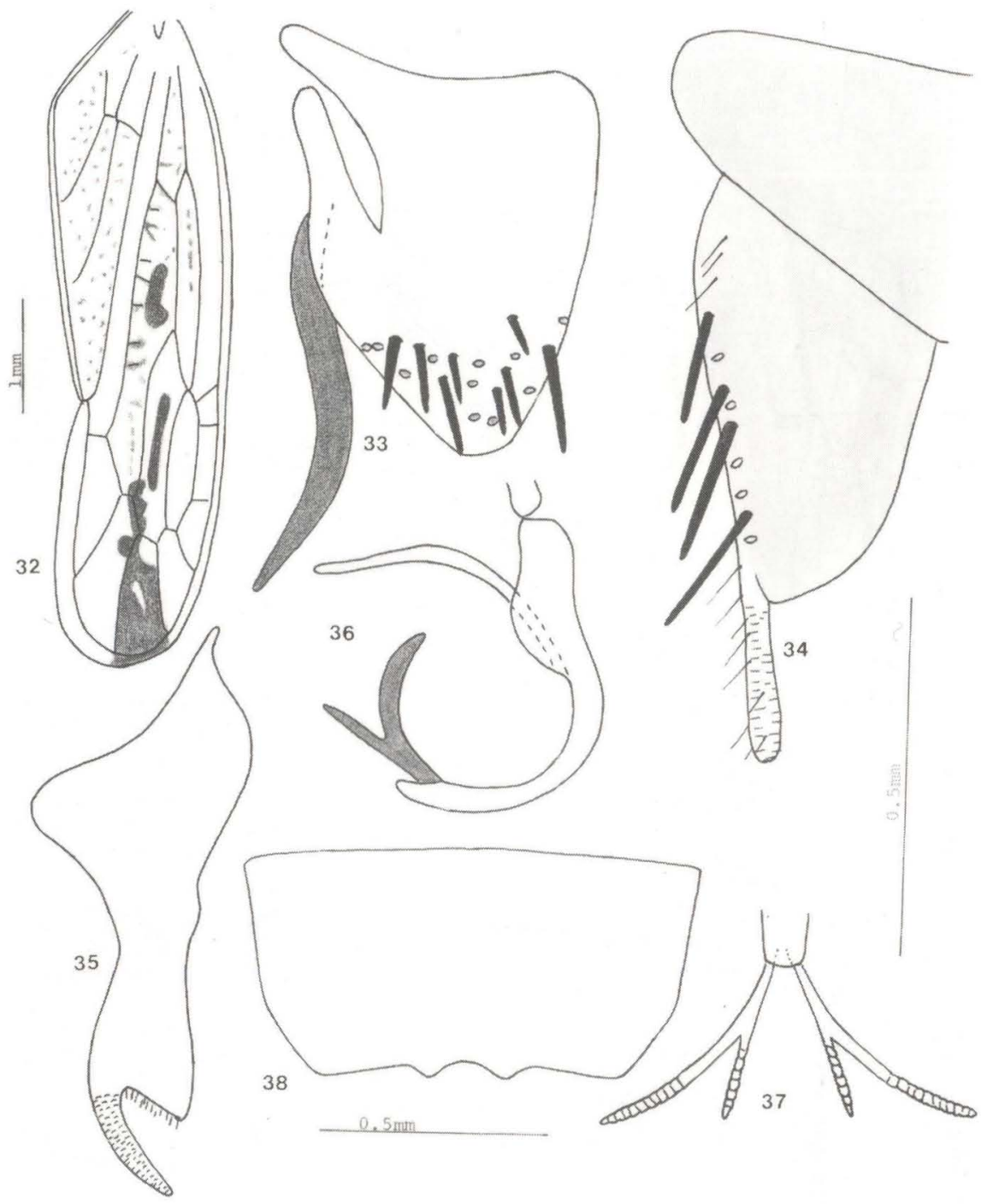

Figs 32-38. Neophlepsius bifidus sp.n.. (32) Tégmina; (33) pigóforo, lateral; (34) valva e placa subgenital; (35) estilo; (36) edeago, lateral; (37) apêndices do edeago, visto de cima; (38) sétimo esternito da fêmea.

Fêmea. Externamente como o macho porém com duas veias extranumerárias na primeira célula apical; uma extranumerária na célula anteapical externa. A veia transversa s-m após a bifurcação da S. Sétimo esternito mais ou menos retangular; margem posterior reta com um lobo arredondado, junto as margens laterais; com uma pequena reentrância no meio e dois pequenos lobos, de cada lado da reentrância.

Comprimento (mm). Macho: 6,50. Fêmea: 6,80. 


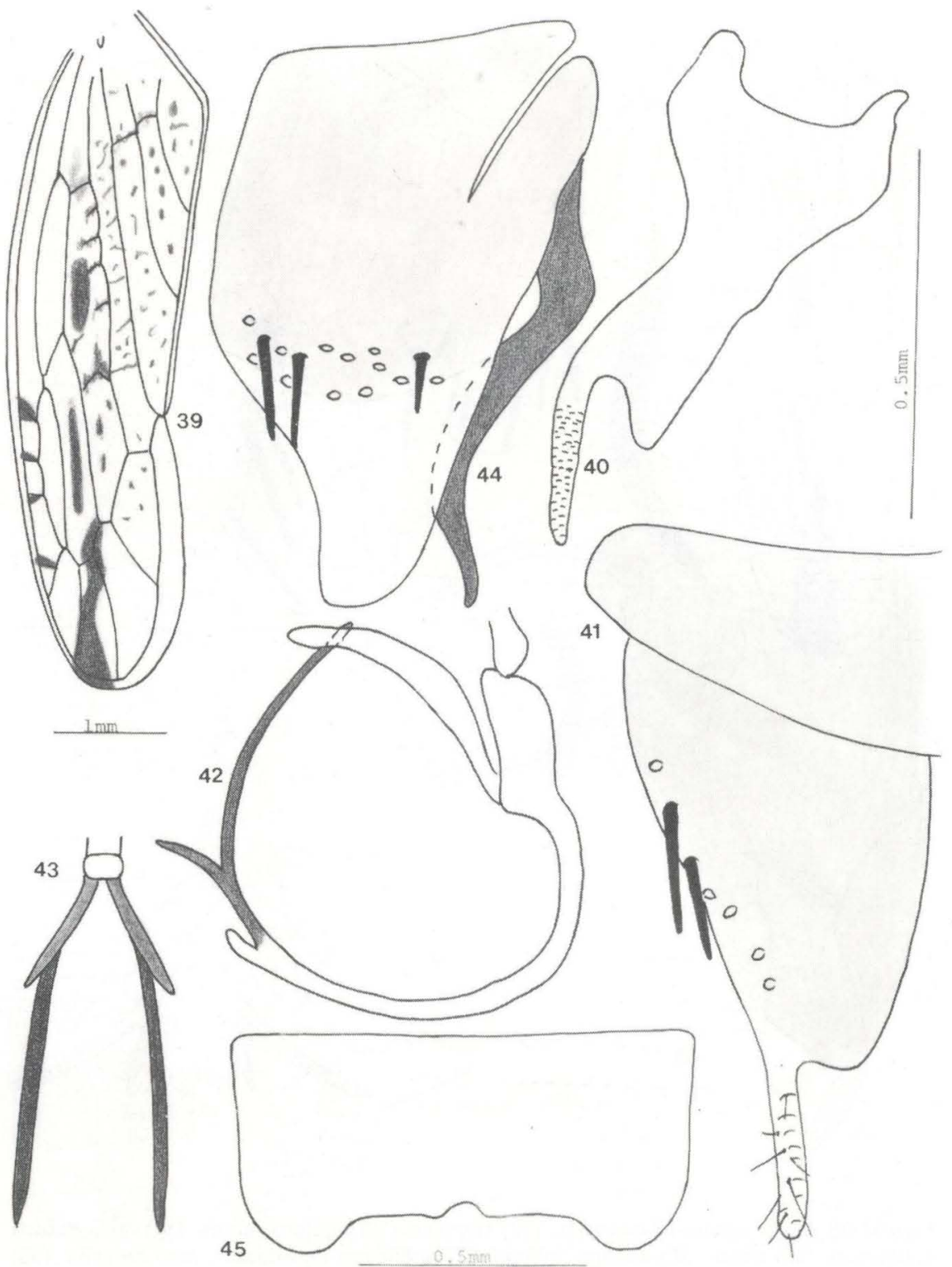

Figs 39-45. Neophlepsius malkowskiae sp.n.. (39) Tégmina; (40) estilo; (41) valva e placa subgenital; (42) edeago, lateral; (43) apêndices do edeago, visto de cima; (44) pigóforo, lateral; (45) sétimo esternito da fêmea.

Material. Holótipo macho. Brasil, Paraná: Ponta Grossa (Vila Velha), 27.VII.1984, A. Lara leg.. Parátipos. Ibidem, 18-21.I.1984, 1 fềmea (DZUP), Ibidem, 18.I. 1984, S. Malkowski leg. (CECI). 
Comentário. Esta espécie aparentemente é próxima de $N$. bifidus e $N$. denticulatus por compartilharem da ausência de dente na placa subgenital e pelos apêndices apicais do edeago.

O nome é dedicado a MSc. Solange Malkowski, responsável pela Coleção Entomológica do Museu do Capão da Imbuia, Curitiba.

\section{REFERÊNCIAS BIBLIOGRÁFICAS}

Berg, C. 1884. Addenda et emendanda ad Hemiptera Argentina. An Soc. Cient. Argent. 18: 117-118.

ChEnG, Y-J. 1980. New leafhopper taxa (Homoptera: Cicadellidae, Deltocephalinae) from Paraguay. Jour. Kans. Ent. Soc. 53 (1): 61-111.

LINNAVUORI, R. 1955. Contributions to the neotropical leafhopper fauna of the family Cicadellidae. IV. Ann. Entomol. Fenn. 21 (2-3): 100-129.

- 1959. Revision of the neotropical Deltocephalinae and some related subfamilies. Ann. zool. Soc. bot. Fennicae Vanamo 20 (1): 1-370.

LinNAVUORI, R. \& D.M. DeLong. 1979. New species of leafhoppers from Central and South America (Homoptera, Cicadellidae, Deltocephalinae, Neobalinae, Xestocephlalinae). Ent. Scand. 10 (2): 123-138.

MENEZES, M. DE. 1973. Notas sobre Deltocephalinae da região neotropical (Homoptera, Cicadellidae). Revta bras. Ent. 17 (20): 131-136

OsBorn, H. 1923. II. Neotropical Homoptera of the Carnegie Museum. Part 2. Records and descriptions of five new genera and sixty-five new species of the subfamily Jassinae. Ann. Carnegie Mus. 15 (1): 27-79.

ZANoL, K.M.R. 1988. As espécies do gênero Neophlepsius Linnavuori, 1955 (Homoptera, Cicadellidae). Revta bras. Ent. 32 (1): 45-53.

Recebido em 30.I.1997; aceito em 05.XI.1997. 